\title{
Editorial:
}

\section{Una Investigación Inclusiva para una Educación Inclusiva}

\author{
F. Javier Murillo ${ }^{1 *}$ \\ Cynthia Duk ${ }^{2}$ \\ ${ }^{1}$ Universidad Autónoma de Madrid, España \\ ${ }^{2}$ Universidad Central de Chile, Chile
}

Seguramente es posible investigar sobre educación inclusiva con procedimientos no inclusivos, pero no parece posible investigar para una educación inclusiva con estrategias excluyentes. Dicho de otra forma, si se quiere que la investigación contribuya a cambiar la realidad, las estrategias investigadoras han de ser coherentes con el cambio buscado.

Al igual que la educación es un acto político, la investigación educativa es profundamente política. Qué se estudie, para qué, para quién, con que enfoques metodológicos, con quién, qué papel juegan los y las participantes, cómo y dónde se difunden los resultados, etc., etc., son opciones profundamente cargadas de política en sentido freiriano: la concepción global del mundo y del ser humano (Murillo e Hidalgo, 2017).

La decisión de investigar sobre Educación Inclusiva que contribuya a desarrollar una educación más equitativa y de calidad para todos y todas, y con ello a una sociedad más inclusiva, democrática y justa necesariamente nos empuja a una investigación de análogas características. Estamos hablando, por tanto, de una investigación inclusiva (democrática y socialmente justa) (Nind, 2014). Y, asumámoslo, la investigación que realizamos no siempre es tan inclusiva, democrática y socialmente justa como nos gustaría.

Podríamos aducir que tradiciones de investigación heredadas de visiones positivistas, impelidas por palabras mágicas como objetividad, fiabilidad y validez, a veces nos ha llevado a tomar decisiones metodológicas alejadas, e incluso incoherentes, con esta finalidad de la investigación. Pareciera que ahora, más que cambiar el mundo, nos mueve que nuestras investigaciones sean publicadas en determinadas revistas, queremos tener muchos JCR (o artículos publicados en revistas indexadas en la ISI of Knowledge). Y está claro que así, o al menos solo así, no se transforma el mundo.

En todo caso, no es nuestro propósito defender la superioridad de un paradigma de investigación sobre otro, ni mucho menos argumentamos en contra de la investigación de carácter cuantitativo, estamos hablando de algo tan sencillo y tan potente como "coherencia". Por ejemplo, la investigación ex post facto nos ayuda a conocer una realidad para cambiarla. Así, si no supiéramos el número de niños y niñas en riesgo de pobreza o las tasas de fracaso y abandono escolar, difícilmente se podrían adoptar políticas y medidas para acabar con ello. Ni tampoco vamos a argumentar que para hacer una investigación inclusiva ha de utilizarse en exclusiva enfoques puramente inclusivos como son la investigación acción, la investigación participativa y emancipatoria, la investigación basada en la participación de la comunidad, la investigación que involucra y recoge la voz del alumnado, o la investigación participativa feminista. Hablamos, simplemente, de coherencia.

*Contacto: javier.murillo@uam.es 
En este sentido, coincidimos con Parrilla y Sierra (2015) que afirman que la investigación inclusiva ha de ser ante todo "una investigación que promueve valores, actitudes y prácticas de investigación inclusivas (p. 164). Una investigación que esté comprometida con la transformación social, con el desarrollo de una educación mejor para una sociedad más inclusiva.

En esta línea, algunas ideas que creemos deben estar en la base de una investigación inclusiva (Apple, 2012; Griffiths, 1998; Murillo e Hidalgo, 2017):

- Investigación de alta calidad. Nada hay más conservador que una mala investigación que solo contribuye a mantener el statu quo.

- Investigación "con", "por" o "para" los participantes, pero en ningún caso una investigación sobre ellos (Parrilla y Sierra, 2015). Ello nos lleva a la idea de democratizar la investigación. "dar la voz" a los discriminados y excluidos es una obligación moral.

- Abordar temas "que importen", que contribuyan a una educación transformadora. Así, por ejemplo, son buenas ideas trabajar con problemáticas "reales" detectadas de un profundo conocimiento de la realidad educativa, enfocarse en temáticas que denuncien situaciones de exclusión e injusticia y desigualdad o relatar experiencias de experiencias de inclusión, de resistencia y cambio.

- Mantener la dialéctica teoría-práctica. Es decir, generar conocimiento y transformar la práctica, aprendiendo de la teoría y de la experiencia, y aprender de prácticas que aporten aprendizajes útiles para la investigación educativa.

- Cuidar la devolución de información. Los resultados de la investigación han de llegar a los diferentes implicados e implicadas; esto hace que sea necesario plantearse una estrategia de comunicación diferenciada para cada colectivo. Las redes sociales son un medio privilegiado, usémoslo.

Pero también aspectos éticos de la investigación (Murillo e Hidalgo, 2017, p. 6):

a) Compromiso inquebrantable con la educación, la sociedad y la lucha por la Justicia Social.

b) Pasión por la investigación y por la educación.

c) Humildad para aprender constantemente, de los errores, de las experiencias y de las personas.

d) Optimismo, casi patológico, hacia la consecución de una mejor educación y una mejor sociedad.

e) Transparencia en las acciones y propósitos.

f) Afán de superación para hacer una mejor investigación.

g) Atrevimiento para plantear nuevos caminos, nuevas estrategias en el diseño, ejecución y difusión de la investigación.

Las palabras de la profesora Ángeles Parrilla (2010), que tan magníficamente ha reflexionado sobre este tema, nos sirven de cierre: 
Para participar en la construcción de esa cultura ética hemos de asumir una actitud crítica y responsable, no rehuir el debate. La educación inclusiva nos invita en definitiva a asumir la tarea investigadora desde una cultura ética responsable, sostenible y comprometida con el desarrollo de aquella investigación que amplía el conocimiento pero que también contribuye a la justicia y la equidad social" (p. 173)

La investigación educativa nunca es neutra, pero la investigación inclusiva debe ser ante todo política. Que implique un fuerte compromiso para lograr una educación más inclusiva, democrática y justa que contribuya a una sociedad más inclusiva, democrática y justa. No hay atajos, o es así, o solo será una pantomima más.

\section{Referencias}

Apple, M. W. (2012). Can education change society? Nueva York, NY: Routledge.

Griffiths, M. (1998). Educational research for social justice: Getting off the fence. Londres: McGraw-Hill Education.

Murillo, F. J. e Hidalgo, N. (2017). Hacia una investigación educativa socialmente comprometida. Revista Iberoamericana de Evaluación Educativa, 10(2), 5-8.

Nind, M. (2014). What is inclusive research? Londres: Bloomsbury Academic.

Parrilla, A. (2010). Ética para una investigación inclusiva. Revista Educación Inclusiva, 3(1), 165174 .

Parrilla, A. y Sierra, S. (2015). Construyendo una investigación inclusiva en torno a las distintas transiciones educativas. Revista Electrónica Interuniversitaria de Formación del Profesorado, 18(1), 161-175. https://doi.org/10.6018/reifop.18.1.214381 